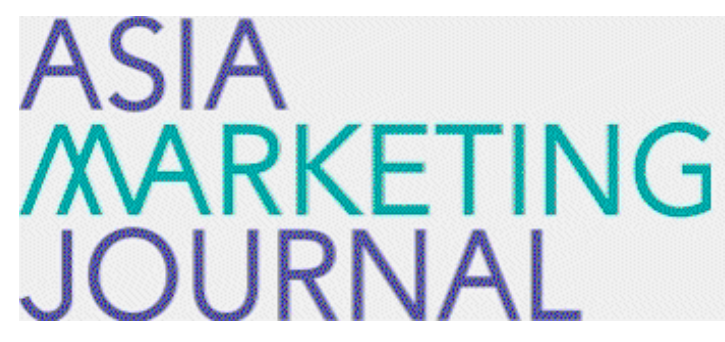

ASIA MARKETING JOURNAL

Volume 20 | Issue 3

Article 1

$10-31-2018$

\title{
Differentiated B2B Marketing Strategy of Dongwon Systems, the No.1 Packaging Solution Company in Korea
}

Mina Jun

Sang Yong Kim

Janghyuk Lee

Koo

Follow this and additional works at: https://amj.kma.re.kr/journal

Part of the Marketing Commons

\section{Recommended Citation}

Jun, Mina; Kim, Sang Yong; Lee, Janghyuk; and Koo (2018) "Differentiated B2B Marketing Strategy of Dongwon Systems, the No.1 Packaging Solution Company in Korea," Asia Marketing Journal: Vol. 20 : Iss. 3 , Article 1.

Available at: https://doi.org/10.15830/amj.2018.20.3.1

This Article is brought to you for free and open access by Asia Marketing Journal. It has been accepted for inclusion in Asia Marketing Journal by an authorized editor of Asia Marketing Journal. 


\title{
Differentiated B2B Marketing Strategy of Dongwon Systems, the No.1 Packaging Solution Company in Korea*
}

\author{
Mina Jun** \\ Sang Yong Kim*** \\ Janghyuk Lee**** \\ Kay Ryung Koo*****
}

\begin{abstract}
Dongwon Systems established in 1977 to exclusively supply Dongwon tuna cans, the parent company. Instead of its stable management and profits by relying on the parent company, the company was not complacent and started innovating and challenging new markets. Dongwon Systems decided to expand the business area and pioneer new markets so that it becomes the first domestic company to successfully expand into independent businesses other than parent company products. Such success of Dongwon Systems was driven by its differentiated B2B strategies. Unlike the characteristics of usual B2B companies, Dongwon Systems has been thinking both of its client companies and end-consumers. In this case-study, we will explore how Dongwon Systems became the No.1 packaging solution company in Korea through technology innovation in the aspects of unique B2B marketing strategy. The key success factor can be summarized in three ways; product and technology development with customer centric mind-set, systematically extending new markets through business diversification, and marking Southeast Asia as a bridgehead for its global strategy. It is expected that the current case study of Dongwon Systems will be able to provide implications for B2C companies as well as B2B companies that try to expand their business portfolio and global business areas through B2B marketing case analysis.
\end{abstract}

Key words: Dongwon Systems, packaging industry, B2B marketing, customer centric mind-set, market expansion strategy

\footnotetext{
* This study is partially supported by Korea University Business School Research Grant.

** Research Professor, Business School, Korea University (phdmina@korea.ac.kr)

*** Professor, Business School, Korea University (sangkim@korea.ac.kr)

**** Professor, Business School, Korea University (janglee@korea.ac.kr)

***** Research Professor, Institute for Business Research \& Education, Korea University (soma1129@korea.ac.kr),

Corresponding Author
} 


\section{Introduction}

Dongwon Systems, a typical B2B company, is a packaging company manufacturing various packaging materials. Dongwon Systems was established to supply tuna can packaging materials for Dongwon Tuna, the parent company, in 1977. The company had a stable sales and profit structure through producing packaging materials for its parent company during its introduction stage.

Despite its stable management and profits by relying on the parent company, the company was not complacent and started innovating and challenging new markets. Since Dongwon Systems foresaw the growing importance of the general packaging industry as well as the growth of the packaging business in the food industry, it decided to expand the business area and pioneer new markets. As a result, it is the first domestic company to successfully expand into independent businesses other than parent company products. Just like Lotte Packaging, currently the second-largest in the same industry, yet exclusively supplies packaging for affiliates of Lotte, in the early stages of Dongwon Systems, its affiliate products for the parent companies accounted for $100 \%$ of sales. However, by 2017, for Dongwon Systems, affiliate products accounted for only $19 \%$, exports and other domestic markets accounted for $81 \%$. Dongwon Systems is currently the largest total packaging company in Korea manufacturing almost all kinds of packaging materials such as plastic bags, glass bottles, cans, PET, aluminum, and color box. Dongwon Systems' success shows how the company has expanded the business to what it is now a challenging and innovative corporation.

More specifically, such success of Dongwon Systems in penetrating the new market was driven by its differentiated B2B strategy and expansion strategy. Beyond the limits of typical strategy of B2B companies, Dongwon Systems took the pioneering spirit of the new market by considering both of its client companies and end-consumers. As Keller (2013) points out that packaging is a considerable factor in marketing products, Dongwon Systems believes that the right packaging can generate strong and significant appeal on the store self and enhance consumption by end-consumers. Dongwon Systems has constantly strived to develop active technologies by closely observing its customers and has always explored customerneeds and developed technology, which resulted in rapid growth.

In terms of its expansion strategy, the company entered new markets through systematic business diversification based on its core competencies. Dongwon Systems successfully expanded into the market for food packaging, the non-food, and eventually, industrial material market and the $\mathrm{B} 2 \mathrm{C}$ market. In virtue of its systematic expansion strategies based on its core competencies, 
Dongwon Systems was able to maximize profits and minimize risks, which contributed to the growth of the corporation. Furthermore, Dongwon Systems has been actively expanding its business overseas. Instead of focusing on the enormous yet saturated North-American market, Dongwon Systems plans to utilize the Southeast Asian market, which is characterized by high growth potentials, as a stepping stone to become a major global brand.

As the largest total packaging company in Korea, Dongwon Systems has the technology and competitiveness to produce high-quality and highly functional packaging materials that increase the customers' values. This is a result of constantly devising how to produce differentiable products by considering both its direct customer companies and end-consumers.

In this case-study, we will explore how Dongwon Systems became the No.1 packaging solution company in Korea through technology innovation in the aspects of unique B2B marketing strategy. The key success factor of Dongwon Systems can be summarized in three ways; product and technology development with customer centric mind-set, systematically extending new markets through business diversification and marking Southeast Asia as a bridgehead for its global strategy. The breakdown of this case is as follows: company background, three key success factors, and conclusion and future direction.

\section{Company Background}

Dongwon Group, the parent company of Dongwon Systems, was established by Chairman, Jae Chul Kim. Chairman Kim is regarded as a mythical figure as he became an owner of a corporation through his challenging spirit despite his relatively humble background as a crew member of a fishing boat. He is also honored for his so-called “director leadership', in which he plays the role of a director who allows his employees to stand out. Such unique leadership and challenging spirit are the driving forces that led to what Dongwon Group is now. He established Dongwon Systems in 1977 to exclusively supply Dongwon tuna cans. This decision reflected the fact that packaging can significantly influence the taste of food and consumption (Keller 2013; Wansink 1996, 2004). Until the early 1990s, Dongwon Systems only focused on producing these tuna cans for its parent company. The first challenge came in 1993, when Dongwon Systems advanced to the packaging industry by producing flexible packaging and plastic containers as well as tuna can packages.

As they expand the business in such manner, in order to meet the increased supply, in 1999 Dongwon Systems established three new flexible packaging facilities located in Jincheon, Cheonan, and Asan. These factories were equipped with the latest facilities and inspection systems, 
〈Figure 1〉 Dongwon System's First Product: Tuna Can (captive market)

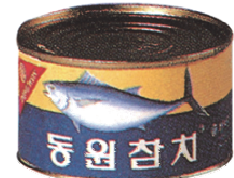

1982


2014
Source: Dongwon Systems internal source

which were able to supply about 3,000 types of flexible packaging materials.

After Jum-Gun Cho promoted to the CEO of Dongwon Systems in 2013, it had grown rapidly as a global company. Based on Dongwon Systems' spirits which are Enthusiasm, Challenge, and Creation, he emphasized the organization's mission which was "corporation needed by society creating new value, and vigorously attempted to enter new markets (see Figure 2). "Creating new values" is simply adding values that are higher such as better lives, more conveniences, higher safety and more health benefits. "To be "a corporation needed by society" we need to actively work for the sound development of society by continuously creating jobs for social stability and fulfilling our responsibilities while seeking profits through corporate activities at the same time. With his strong will and outstanding leadership, Dongwon Systems prepared for the future of the global packaging industry that will inspire consumers and make a healthier planet.

Under the CEO Cho's challenging spirit,

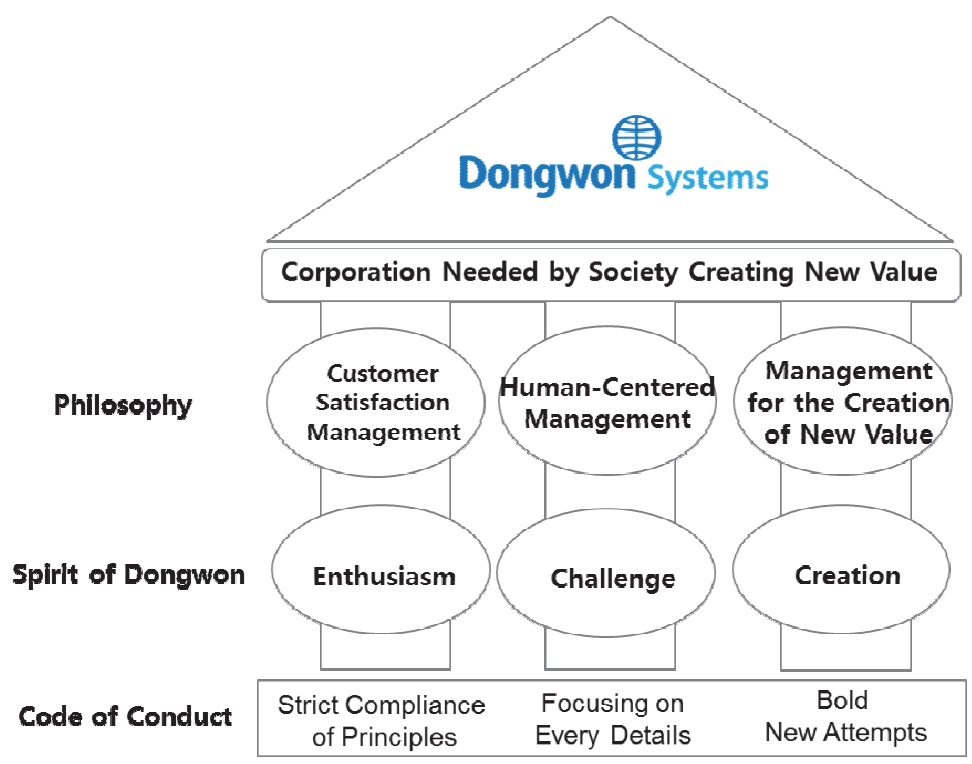

(Source: Dongwon Systems' official website) 
Dongwon Systems started to expand business not only in packaging materials business but also in other fields by aggressively implementing business diversification. Firstly, the company expanded target markets to other food-related business. Moreover, in order to exploit the new market, the company will advance not only to the food industry, which was a concentrated industry group, but also to the non-food market. Thanks to the successful market extension, the share price, which was less than 10,000 won at the time of his inauguration, rose dramatically in 2 years, to over 60,000 won in 2015.

Despite such achievements, Dongwon Systems did not remain in domestic markets and strived to extend to the global market, as the company acquired Talofa Systems at American Samoa, Techpack Solution for glass and PET bottle industry and Hanjin P\&C for printing technology in 2015. Furthermore, the company developed a global supply chain network by acquiring Tan Tien Packaging and Minh Viet Packaging which are the largest packaging companies in Vietnam.

Dongwon Systems currently owns ten domestic packaging materials business sites and three overseas subsidiaries including U.S., Canada, and Vietnam. Total revenues have been continuously increased, and revenues in 2017 totaled KRW 1,283 billion, including overseas subsidiaries' sales, and KRW 227.6 billion in exports (see Figure 3).

Dongwon Systems has been enhancing its expertise and advanced systems in all areas of packaging materials, such as flexible packaging, bottles, cans, industrial films and aluminum foils. They are now transforming themselves into a global total packaging specialist for customers around the world.

〈Figure 3〉 Sales of growth of Dongwon Systems

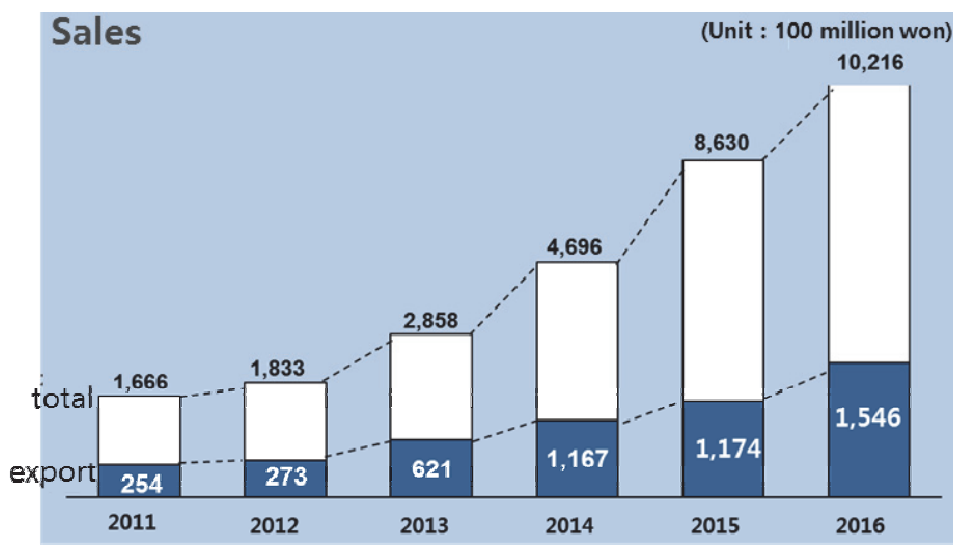

(source: Dongwon Systems internal source) 


\section{Key Success Factors}

\subsection{Focusing on Technology Development with Customer Centric Mind-Set}

Traditionally, B2B companies made buying decisions based on increasing profitability, reducing costs and enhancing productivity whereas B2C companies focused on their end-customers and their needs and satisfaction (Maechler, Sahni, and Oostrum 2016). Although such customersatisfaction improvement is typically associated with B2C players, Dongwon Systems determined it to be the critical factor in the B2B setting. More importantly, Dongwon Systems has delved into the competitive advantages of developing more customer-centric products and also focused on the end consumers' satisfaction.

Packaging is known to be one of the important brand elements along with brand name, logo, slogan, etc. (Keller 2013) (see Figure 4). Also, the packaging's basic function is considered to identify the product and facilitate product protection (Demetrakakes 2009; Bassin 1988). Furthermore, packaging is the first component that the consumers encounter at the "moment of truth"- the point of purchase (Keller 2013; Serafin 1985). Therefore, Dongwon Systems believes that the packaging of their clients' products is crucial to their clients' product quality, thus they constantly invest in the design and technology of the packages.
〈Figure 4〉 Brand elements

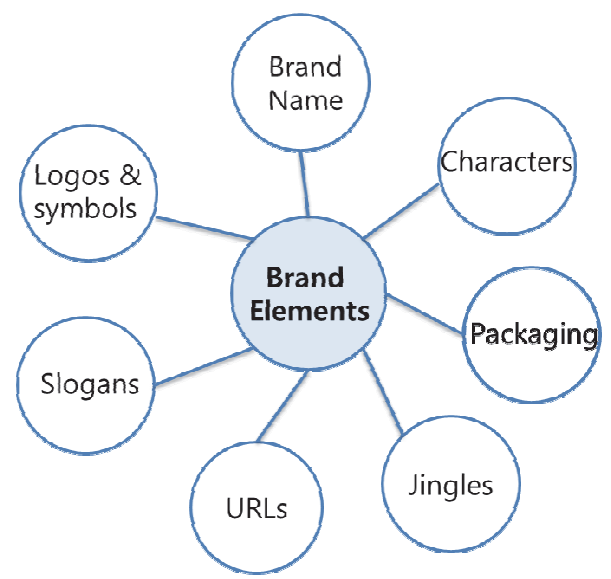

(Source: Strategic Brand Management $4^{\text {th }}$ edition)

In order to develop the most convenient and practical packaging products, Dongwon Systems identifies the consumers' needs through constant consumer research on not only its client companies but also their end-customers. Dongwon Systems' such efforts could be categorized into the following three strategies; (1) maximizing corporate clients' satisfaction through closely monitored operation, (2) satisfying end-customers' needs through technology innovation with product driven aspects, (3) developing technology that aims to minimize costs for the client companies.

\subsubsection{Closely monitored operation}

Most B2B corporations merely concentrate on manufacturing the desired products of the clients, and hardly ever invest in developing new technology. However, Dongwon Systems has autonomously developed packaging merchandise 
that is to be offered to the clients, which is known as 'Closely Monitored Operations,' instead of passively producing the products that the clients require. This is because Dongwon Systems believes that the packaging of its clients' products directly represents its clients' product quality.

One of the most successful packaging products is the development of stick-typed Spout Pouch used in pharmaceuticals (see Figure 5). This is a packaging material that is easy to carry and easy to cut, derived from the inconvenience that consumers have been experiencing in the past, which has brought satisfaction to both pharmaceuticals and consumers.

In addition, the successful commercialization of this product had a special strategy. Usually, most B2B companies develop the products needed by contracted customer companies. Dongwon Systems, however, developed the packaging product that was able to solve the inconveniences of consumers in advance and subsequently visited large pharmacies in the Jongno area, downtown of Seoul, directly to find the most suitable companies who want to purchase their new product, the Spout Pouch.
The salespeople found the most suitable pharmacy company by explaining and asking pharmacists who would be in need of their product the most. They contacted several pharmaceutical companies to propose their new product, and eventually, one pharmaceutical company signed a contract. This contributed to a large portion of the sales for Dongwon Systems as well as the pharmaceutical company.

Such Spout Pouch packaging was also applied to wine packaging, which created a new packaging group that got rid of previous stereotypes (see Figure 6). Instead of the unhandy glass bottle, the wine would be put in the spout pouch to make wine more lightweight and portable. Currently, the Spout pouch-packaged wine is being sold in many restaurants and marts and is receiving positive reviews.

\section{〈Figure 6〉 Spout Pouch Packaging for Wine}



(Source: Dongwon Systems internal source)

〈Figure 5〉 Pharmaceutical packaging with Stick-typed Spout Pouch
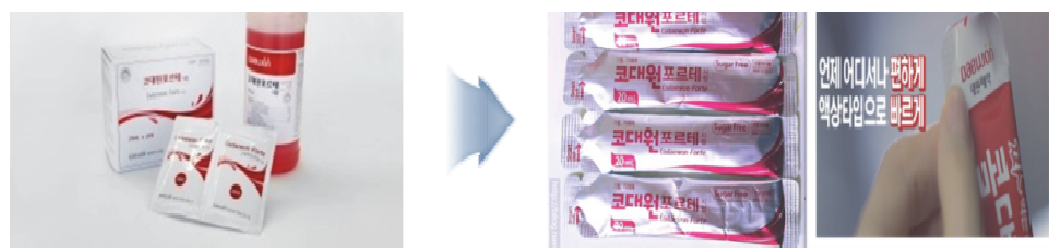

(Source: Dongwon Systems internal source) 
Another example is the aluminum can bottle, which was developed based on the end-consumers' needs and offered to client corporations. The two-piece aluminum can bottle that Dongwon Systems had introduced for the first time in Korea is greatly contributing to enhanced portability through resealing, and such development of cans presents high quality image for the beverages they contain (see Figure 7). The two-piece aluminum can body is safer to use and also environment-friendly than the onepiece bottle can. The advantages of the twopiece aluminum can are convenience, simple sealing, light weight, and recyclability.

\section{〈Figure 7〉 Two-Piece Aluminum Can}
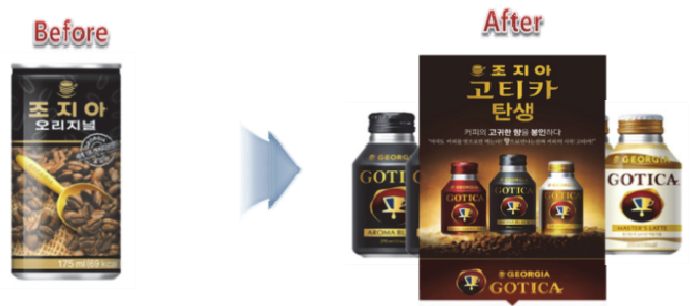

(Source: Dongwon Systems internal source)

Thanks to this constant development, as for the bottle market, Dongwon Systems satisfied $25 \%$ of the domestic demand by meeting the precise needs of global enterprises like $A B$ Inbev and Coca-Cola and $40 \%$ of the domestic demand for glass bottles for large domestic corporations.

\subsubsection{Technology innovation with product driven aspect}

The mainly distinguished characteristic of $\mathrm{B} 2 \mathrm{~B}$ companies from B2C companies is that $\mathrm{B} 2 \mathrm{~B}$ is a relation driven industry. However, the main driving force behind Dongwon Systems' growth has been its unique innovativeness based on the consumer-based product driven strategy. Dongwon Systems identified the consumers' needs through constant consumer research and customer satisfaction surveys in order to come up with convenient and practical packaging products. Consequently, they have been constantly innovating technologies and R\&D such as temperature maintenance technology, anticounterfeiting technology, and product renewal by concentrating improvement of the product itself.

The first product is the food stick-packaging featuring with laser easy-cut, which is the company's the most influential technology and widely recognized in the market (see Figure 8). Dongwon Systems' consumer department recognized that when the end-customers attempted to unseal the vinyl packaging, they tended to spill the contents or felt inconvenient because the vinyl packages were relatively difficult to tear. With this discovery, Dongwon Systems undertook research to alleviate the problem caused by the stiff vinyl packaging and as a result, successfully developed a package that adopted laser technology. This was called 
〈Figure 8〉 Food Stick Packaging with Laser Easy-Cut Technology
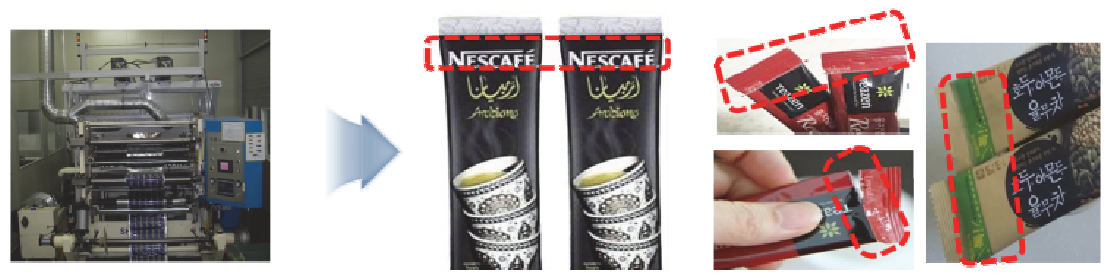

(Source: Dongwon Systems internal source)

the 'Laser Easy-Cut' and was successfully commercialized. End consumers were content with this kind of packaging, as most consumers found the technology very useful.

The second product is the Zion ink, which is a type of specialized ink that utilizes temperature maintenance technology (see Figure 9). The product could be exposed under various temperature range conditions and thus was mainly applied to the packages of mask pack products. Zion ink is usually adjusted to emit at temperatures below $10^{\circ} \mathrm{C}$, helping consumers use the mask pack at the optimum temperature. This also contributes to the anti-counterfeiting effect, which enables identification of counterfeit products and safe use of the product. In addition, the application of Zion ink makes it possible to present the coloring power of various colors, thus enhancing the mask pack products' aesthetics.

Other than developing new packaging models, Dongwon Systems has also been capitalizing on the trust gained by acquiring various quality certifications to provide all technical services quickly and accurately to customers. It strives to make the best products and acquire numerous globally recognized certifications from organizations such as the US-based Coca-Cola and Pepsi and the 正 Mark of Japan's Ministry of Economy, Trade and Industry. This qualifies them to produce for global corporations.

〈Figure 9〉 Temperature Maintenance Technology


(Source: Dongwon Systems internal source)

\subsubsection{Suggestion of customer's cost reduction technology: An example of Corning Inc.}

By continuously maintaining and developing relationships with customers and excellent after-sales service, Dongwon Systems even suggested that their technology can reduce 
customer companies' costs. Corning Inc., an American multinational technology company that specializes in specialty glass, ceramics, and related material, is one of the largest customers of Dongwon Systems. The company simplified the Corning Inc's production processes and reduced its costs through joint development with customers by developing an embossing surface protection film for LCD glass (see Figure 10).

〈Figure 10〉 Embossing Surface Protection Film for Corning Inc.
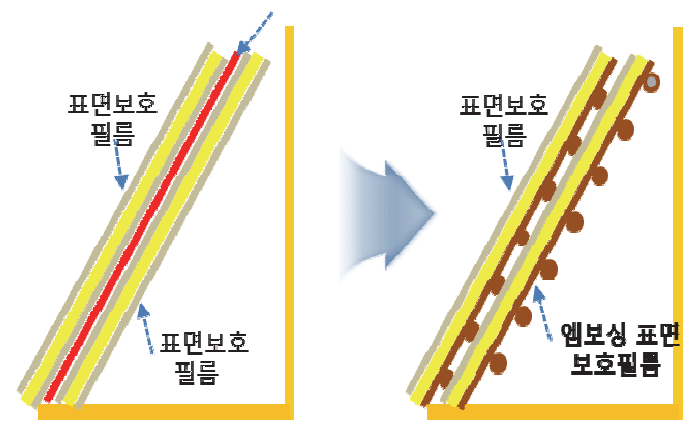

(Source: Dongwon Systems internal source)

Before the improvement, the protective film was used between the laminated glasses to facilitate separation when taking out the glass one by one. However, after the improvement, the embossed protective film is laminated on one side of the glass so that the laminate was not needed when taking out the glass. This not only simplifies the process (elimination of the laminate handling process) but also contributes to the reduction of the manufacturing cost of the customer by increasing the efficiency of the process. Through such technology, they reduced a total of KRW 360 billion in terms of costs during the partnership with Corning (see Table 1).

Dongwon Systems is working hard to develop new materials so that the company can provide the best solutions to meet the mercurial needs of customers such as reducing the weight of materials and prolonging storage periods, which are the current trends within the industry.

As can be seen, Dongwon Systems has continuously searched for their clients' and consumers' needs and rightly applied them to engage in proactive product development. Through such actions, Dongwon Systems has been maximizing customer satisfaction and expanding their business.

\subsection{Extending New Market through Business Portfolio Diversification and Pioneering Market}

Dongwon Systems started to expand its business not only in packaging materials business but

〈Table 1〉 Dongwon Systems' Sales generated by cost reduction technology from 2014 to 2017

\begin{tabular}{|c|c|c|c|c|}
\hline & 2014 & 2015 & 2016 & 2017 \\
\hline Sales & 300 & 287 & 298 & 296 \\
\hline
\end{tabular}

(unit: 100 million won) 
also in other fields by aggressively implementing a business diversification strategy. Despite its stable management and profits in its early stage during 1977-1993, the company was not complacent and started innovating and challenging new markets instead of relying on the parent company. As the starting point, it moved away from the supplying tuna can packages for its parent company product and moved towards other food-related markets such as packaging for coffee, beverage, and snacks using Dongwon Systems' main competence and technology. In addition, other than its high-end technology, the company also has comparative advantages in its facilities. Although Dongwon Systems does not produce food, the company has been enhancing the cleanness of its facilities and environment to a high level of standards. The company has acquired several food-safety management certifications, the ISO international certification and FSSC (Food Safety System Certification) in order to meet the requirements of the quality of foods and the sanitary conditions that food companies would have. Due to the fact that Dongwon Systems had such facilities that were optimized for food packaging, it was able to successfully expand into other food industries. As a result, most of the food packaging that the end consumers easily encounter, for example, Nescafe, Coca-cola, Tester's Choice, Hite, and M\&M, is produced by Dongwon Systems.

The next step they took was to expand its efforts to diversify its market to the non-food industry such as paper packaging and cosmetics packaging and even to the secondary battery industry as well. By applying Dongwon Systems' previous technologies to the cosmetic industry, specifically the facial mask pack industry, the company successfully extended its business to non-food market. Moreover, since Dongwon Systems had been working with the food industry in which the cleanness and freshness of the production environment are crucial factors, packaging for cosmetics, which also needs clean maintenance of materials, is very well-matched. In addition, Dongwon Systems' various advanced technologies such as layer cut, spout pouch, protecting UV, and anti-counterfeiting has brought considerable benefits to be positioned in a superior status than other competitors in the cosmetic industry (see Figure 11).

The third procedure was to engage in developing industry goods as well as consumer goods. In 2013, the company entered the aluminum business and expanded its materials business (see Figure 12). By using its own technology, Dongwon Systems produces and supplies cooling and heating fins for air-conditioners and automobiles, condenser foil for electronic parts, transformers and various types of pipes and construction materials, for secondary batteries and electronic components. Particularly, Dongwon Systems' aluminum division occupies a unique position in the domestic aluminum foil industry as it has consistently improved its quality and productivity. 
〈Figure 11〉 Various Examples of Mask Pack with New Technology Development

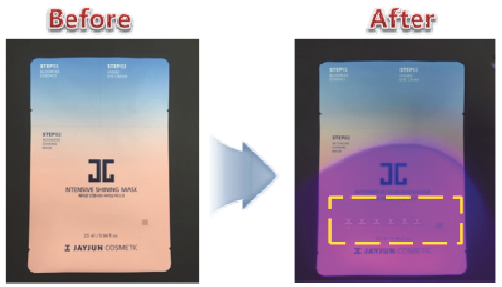

Anti-counterfeiting Package for Mask

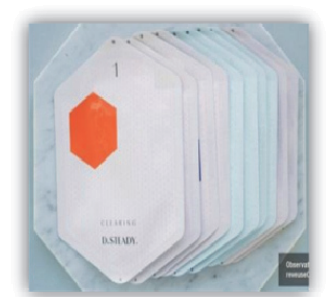

Pouch with Protecting UV Technology

(80 95\% level of protection)

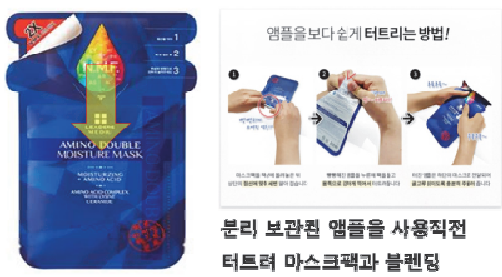

Fragible mask pack with seperately packaged ample

(Source: Dongwon Systems internal source)
〈Figure 12〉 Electronic Components for Secondary Batteries and Auxiliary Battery for Electronic Cars
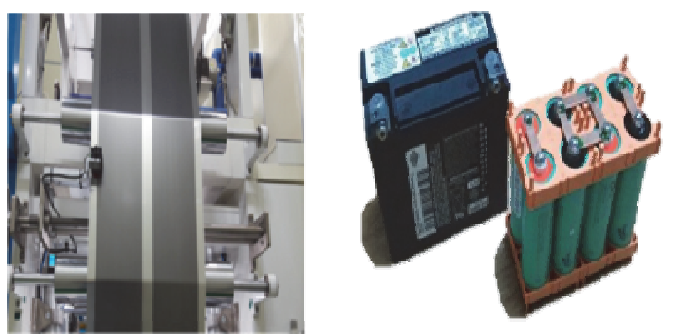

(Source: Dongwon Systems internal source)

More importantly, Dongwon Systems recently even started to produce its own B2C products in the cosmetic industry. With its core technology related to materials, the company launched a B2C product by cooperating with Cinq de Beaute, a premium mask care brand (see Figure 13). Dongwon Systems utilized a substance that they previously developed called elastic non-woven fabric to create a mask pack with maximized efficiency. Cinq de Beaute's products are sold in beauty stores all over Korea. Dongwon Systems is planning to continue exploiting their technology in order to come up with various B2C products.

〈Figure 13〉 Hand, Foot and Hair Mask Pack with Elastic Non-Woven Fabric
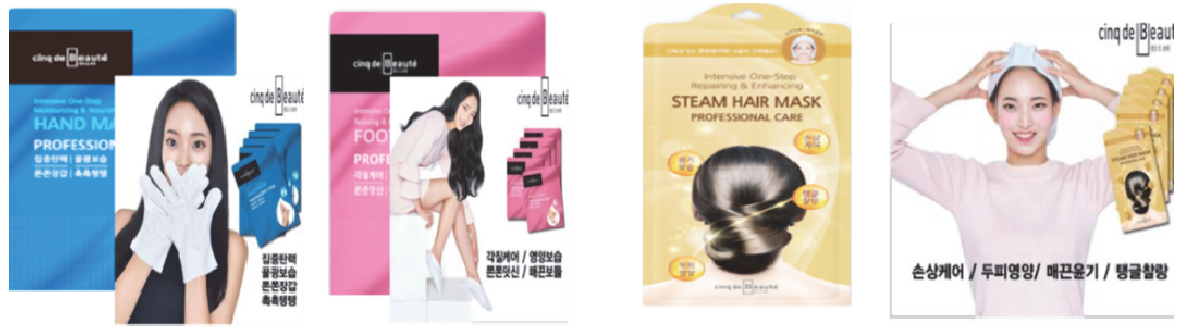

(Source: Dongwon Systems internal source) 
Thus, Dongwon Systems is making progress by maximizing profits and minimizing risks. With the systematic expansion strategies based on its core competencies, the company was able to successfully extend its business from food packages to industry materials and even to the $\mathrm{B} 2 \mathrm{C}$ industry.

\subsection{Marking Southeast Asia as a Bridgehead for Global Strategy}

Even though Dongwon Systems is the largest company in the domestic market, the company is not complacent with its success in Korea and explores new markets. In order to extend to the global market, Dongwon Systems first acquired Talofa Systems at American Samoa, Techpack Solution for glass and PET bottle industry and Hanjin P\&C for printing technology in 2015.
However, instead of focusing on the massive yet overly competitive North American market, Dongwon Systems targeted the rapidly growing Asian market that could be their bridgehead to global success. Dongwon Systems is pursuing expansion of exports to neighboring countries of Asia by having a central base with the network of multinational companies (see Figure 14). Among South Asia, they decided to aggressively enter Vietnam which has a big potential in market growth with $6.8 \%$ of economic growth rate last year. It aims to strengthen production capacity which can lead great cost competitiveness in the global market. The company started full-fledged global operations and developed a global supply chain network by acquiring Tan Tien Packaging and Minh Viet Packaging which are two largest packaging companies in Vietnam. Also, the company established a factory in Ho Chi Minh, South of

〈Figure 14〉 Global Expansion by Marking Southeast Asia as a Bridgehead



(Source: Dongwon Systems internal source) 
Vietnam and recently, expanded the plant in Vietnam, which required investments worth approximately US \$10 million on March 15, 2018. In other plants, mass production began in Bac Ninh, northern Vietnam. Various packaging products produced at the factory are supplied to more than 200 global companies such as Unilever, P\&G, Ajinomoto, and Pepsi.

As a result, Dongwon Systems has been able to accelerate the expansion of its business by operating a large-scale factory both in the northern representative city of Hanoi and Ho Chi Minh, south of Vietnam. With the plants in northern and southern areas as the starting point, Dongwon Systems will be able to largely promote exports not only to Vietnam but also to countries throughout Asia. Through such global market extension strategies of targeting Southeast Asia as a stepping stone for further expansion, Dongwon Systems currently owns ten domestic packaging materials business sites and three overseas subsidiaries including U.S., Canada, and Vietnam. Through such diversification of global market strategy, Dongwon Systems was able to expand its business range to 30 countries. In fact, Dongwon Systems is an official vendor of Nestle which is an influential global food company of 150 years history. Total revenues in 2017 totaled KRW 1,283 billion, including overseas subsidiaries' sales, and KRW 227.6 billion in exports. Dongwon Systems won the $\$ 100$ million Export Tower Prize in 2017 from the Korean government.

\section{Conclusion and Future Direction}

Dongwon Systems, which set value creation for its customers as the first priority and relentlessly challenged its potential, has written the history of packaging innovation in Korea. In this case-study, we examine how Dongwon Systems become the No.1 packaging solution company in Korea through technology innovation in the aspects of unique B2B marketing strategy. The key success factor can be summarized in three ways; product and technology development with customer centric mind-set, systematically extending new markets through business diversification, and marking Southeast Asia as a bridgehead for global strategy.

The first factor is the development of various products through a customer centric mind-set. This was the main point of difference from competitors and existing B2B corporations. Dongwon Systems has delved into the competitive advantages of developing more customer-centric products and also focused on the end consumers' satisfaction.

The second factor was the company entering new markets through business diversification. Initially producing tuna cans, Dongwon Systems successfully expanded into the market for various food packaging and eventually, with its core competencies, extended into the nonfood business such as cosmetics. Moreover, through consistent technological advancements, 
it entered the industrial material market and the B2C market for auxiliary batteries and mask packs, respectively. In virtue of its systematic expansion strategies based on its core competencies, Dongwon Systems was able to maximize profits and minimize risks, which contributed to the growth of the corporation.

Finally, unsettled with being the leader in the domestic market, Dongwon Systems is taking the initiative to pioneer the global market with its Southeast Asian bridgehead strategy. Instead of focusing on the massive yet overly competitive North American market, Dongwon Systems has aggressively invested the rapidly growing Asian market, especially the Vietnamese market that could be their bridgehead to global success

Based on the Dongwon Systems' such outstanding strategies and huge success, we are looking forward to seeing that Dongwon Systems will achieve its ultimate goal of becoming a global leading packaging company by developing environment-friendly packaging materials that will be useful in everyday life, as well as advanced materials for electronics components.

〈Received June 8. 2018〉 〈Accepted August 21. 2018〉

\section{References}

Bassin, Susan B. (1988), "Value-Added Packaging Cuts through Store Clutter," Marketing News, 26, September, 21.

Demetrakakes, Pan (2009), "Packaging Innovator of the Decade," Food and Beverage Packaging, 1 April.

Dongwon Systems (2018), Dongwon Systems' Official Website,

http://www.dongwonsystems. com

Keller, Kevin L. (2013), Strategic Brand Management: Building, Measuring, and Managing Brand Equity, Fourth Edition, Pearson Education.

Maechler, Nicolas, Sanjeev Sahni, and Martine van Oostrum (2016), "Improving the Business-to-Business Customer Experience," McKinsey \& Company, March, http://www.mckinsey.com

Serafin, R. (1985), Packaging Becomes an Art, Advertising Age, 12, 66.

Wansink, Brian (1996), “Can Package Size Accelerate Usage Volume,?" Journal of Marketing, 60 (July), 1-14.

Wansink, Brian (2004), "Environmental Factors

That Increase the Food Intake and Consumption Volume of Unknowing Consumers," Annual Review of Nutrition, 24, 455-479. 